\title{
Electrochemical reduction of graphene oxide films: Preparation, characterization and their electrochemical properties
}

\author{
ZHANG Xiong, ZHANG DaCheng, CHEN Yao, SUN XianZhong \& MA YanWei* \\ Institute of Electrical Engineering, Chinese Academy of Sciences, Beijing 100190, China
}

Received December 17, 2011; accepted March 6, 2012; published online June 1, 2012

\begin{abstract}
Graphene oxide (GO) film was electrochemically reduced by a cyclic voltammetry technique in 6 mol L $\mathrm{L}^{-1} \mathrm{KOH}$ aqueous solution. Electrochemically reduced graphene oxide (ER-GO) film was characterized by X-ray diffraction, X-ray photoelectron spectroscopy, atomic force microscopy, and Raman spectroscopy. The oxygen content (with the O/C atomic ratio of $1.29 \%$ ) was significantly decreased after electrochemical reduction. The ER-GO film exhibited a specific capacitance of $152 \mathrm{~F} \mathrm{~g}^{-1}$ at the current density of $5 \mathrm{~A} \mathrm{~g}^{-1}$ and a good rate capability. Furthermore, the ER-GO film showed an excellent cycling ability. The capacitance retention remained $99 \%$ after 3000 cycles at the current density of $10 \mathrm{~A} \mathrm{~g}^{-1}$.
\end{abstract}

graphene, electrochemical reduction, electrochemical double-layer capacitor, electrode material

Citation: Zhang X, Zhang D C, Chen Y, et al. Electrochemical reduction of graphene oxide films: Preparation, characterization and their electrochemical properties. Chin Sci Bull, 2012, 57: 3045-3050, doi: 10.1007/s11434-012-5256-2

Graphene, a two-dimensional carbon material consisting of a single-layer of $\mathrm{sp}^{2}$ carbon atoms, has attracted strong scientific and technological interest due to its unique physical and chemical properties, such as high surface area, excellent conductivity, and mechanical strength [1,2]. Graphene has shown great applications in nanoelectronics [3], biosensors [4], nanocomposites [5-8], batteries [9,10], electrochemical double-layer capacitors (EDLCs) [11-19], and so on.

Generally, several techniques, such as micromechanical cleavage [20], epitaxial growth on silicon carbide or metal [21], chemical vapor deposition [22], thermal exfoliation [23], and chemical reduction of graphene oxide (GO) [24,25], have been developed to produce graphene. The chemical reduction of graphene oxide is considered to be the most economical way to the mass production of graphene [26]. However, it often employs hazardous chemicals (e.g. hydrazine) as reductants and thus this technique is not a green approach to the synthesis of graphene. Recently, electrochemical reduction of graphene oxide to produce graphene has received a great attention since it can be performed without any dangerous chemicals. $\mathrm{NaCl}$ [27-29], $\mathrm{Na}_{3} \mathrm{PO}_{4}$

*Corresponding author (email: ywma@mail.iee.ac.cn)
[30], $\mathrm{Na}_{2} \mathrm{SO}_{4}$ [31], $\mathrm{NaNO}_{3}$ [32], $\mathrm{PBS}\left(\mathrm{K}_{2} \mathrm{HPO}_{4} / \mathrm{KH}_{2} \mathrm{PO}_{4}\right)$ [33], $\mathrm{KNO}_{3}$ [34] and $\mathrm{KCl}$ [35] aqueous solutions and organic solvents [36] have been investigated as mediums for the electrochemical reduction of graphene oxide. However, an efficient route to fabricate electrochemically reduced graphene oxide (ER-GO) films with lower oxygen content is still a challenge.

In this paper, we reported a simple, efficient, and environmentally friendly electrochemical method to reduce GO in $6 \mathrm{~mol} \mathrm{~L}^{-1} \mathrm{KOH}$ using cyclic voltammetry scans from -0.9 to $0 \mathrm{~V}$ (vs. $\mathrm{Hg} / \mathrm{HgO}$ ). This is a positive effect of deoxygenation of GO under the strongly alkaline solution [37]. The resulted ER-GO film showed a low O/C ratio of 1.29\% determined by X-ray photoelectron spectroscopy (XPS). A specific capacitance of $152 \mathrm{~F} \mathrm{~g}^{-1}$ was obtained for the ERGO film at the current density of $5 \mathrm{~A} \mathrm{~g} \mathrm{~g}^{-1}$. Moreover, the ER-GO film exhibited a good rate capability and an excellent cycling performance.

\section{Experimental}

Graphite oxide (GO) was synthesized from natural graphite 
(100 mesh, Alfa Aesar Co.) by the modified Hummers method [38]. An amount of $20 \mathrm{mg}$ GO was mixed with 20 $\mathrm{mL}$ deionized water, and a certain polytetrafluoroethylene (PTFE) solution was added into the mixture (the weight ratio of GO/PTFE at 9:1). Then, the mixture was ultrasonicated for $2 \mathrm{~h}$ to give a stable brown dispersion. The $\mathrm{GO} /$ PTFE film was prepared by cast-dropping onto platinum sheets and drying at $70^{\circ} \mathrm{C}$ in air. The electrochemical reduction of GO was carried out with cyclic voltammetry $(\mathrm{CV})$ in $6 \mathrm{~mol} \mathrm{~L}^{-1} \mathrm{KOH}$ solution in a standard three-electrode cell with the $\mathrm{Hg} / \mathrm{HgO}$ and platinum sheet as the reference and counter electrode, respectively. Cyclic voltammetry scans were recorded from -0.9 to $0 \mathrm{~V}$ (vs. $\mathrm{Hg} / \mathrm{HgO}$ ), using a $\mathrm{CHI}$ $660 \mathrm{C}$ electrochemical workstation. The electrochemical impedance spectroscopy (EIS) was measured in the frequency range of $10 \mathrm{mHz}$ to $100 \mathrm{kHz}$ at $0 \mathrm{~V}$ with an $\mathrm{AC}$ amplitude of $5 \mathrm{mV}$. Galvanostatic charge-discharge test was performed by an Arbin MSTAT4 multichannel galvanostat/ potentiostat.

$\mathrm{X}$-ray diffraction (XRD) patterns were performed using an X' Pert Pro system with $\mathrm{Cu} \mathrm{K} \alpha$ radiation. X-ray photoelectron spectroscope (XPS) spectra were recorded on a PHI Quantear SXM (ULVAC-PH INC) which used Al as anode probe in $6.7 \times 10^{-8} \mathrm{~Pa}$. Atomic force microscopy (AFM) images were recorded on a digital Instruments Nanoscopy IIIa atomic force microscope. Raman spectra were obtained on a RM 2000 microscopic confocal Raman spectrometer (Renishaw in via Plus, England) employing a $633 \mathrm{~nm}$ laser beam.

\section{Results and discussion}

GO was electrochemical reduced with potential cycling at $50 \mathrm{mV} \mathrm{s}^{-1}$ in $6 \mathrm{~mol} \mathrm{~L}^{-1} \mathrm{KOH}$ (from -0.9 to $0 \mathrm{~V}$, vs. $\mathrm{Hg}$ / $\mathrm{HgO}$ ). Figure 1 shows the $\mathrm{CV}$ curves during the reduction process from the 1st to 1000th cycle. The GO film exhibits three redox peaks at about $-0.18,-0.61$, and $-0.72 \mathrm{~V}$, respectively. The redox peaks are possibly due to the following reported surface redox reactions [39-41]:

$$
\begin{aligned}
&>\mathrm{C}-\mathrm{OH} \leftrightarrow>\mathrm{C}=\mathrm{O}+\mathrm{H}^{+}+\mathrm{e}^{-} \\
&>\mathrm{C}=\mathrm{O}+\mathrm{e}^{-} \leftrightarrow>\mathrm{C}-\mathrm{O}^{-} \\
&-\mathrm{COOH} \leftrightarrow-\mathrm{COO}+\mathrm{H}^{+}+\mathrm{e}^{-}
\end{aligned}
$$

It can be seen that the redox peaks decrease (to disappear) as the potential cycling proceeds due to the quasireversible reactions. Moreover, the cathodic and anodic currents increase linearly and the $\mathrm{CV}$ curves become almost unchanged after the 400th cycle, which suggests that the electrochemical reduction of GO is considered to be completed. The change in shape of the CV curves demonstrates the increase of non-Faradaic currents induced by the increase in effective surface area of electrically conductive graphene that are obtained by reduction of GO [36].

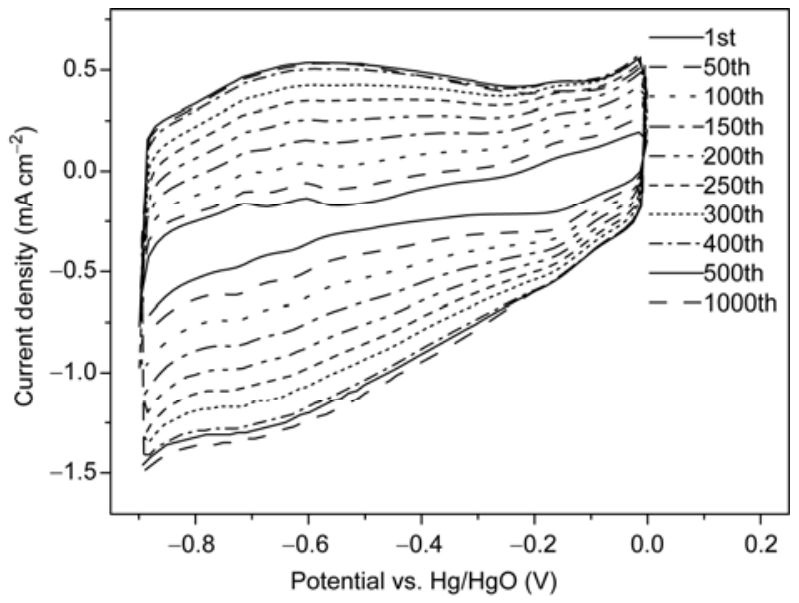

Figure $1 \mathrm{CV}$ curves of the electrochemical reduction of the GO film in $6 \mathrm{~mol} \mathrm{~L}^{-1} \mathrm{KOH}$ at $50 \mathrm{mV} \mathrm{s}^{-1}$ from 1st to 1000th.

Figure 2 shows the XRD patterns of the GO and ER-GO films. A clear diffraction peak is observed for the $\mathrm{GO}$ film at $2 \theta=9.91^{\circ}$ corresponding to an interlayer distance of $8.9 \AA$. After the electrochemical reduction of the GO film, the characteristic peak of GO disappears, which indicates that the interlayer distance of ER-GO is considerably reduced by removal of oxygen-containing functional group. A new diffraction peak of graphite (002) at $26.46^{\circ}$ appears, as reported in previous work [42]. The van der Waals attraction between two adjacent layers becomes dominant as compared to those of surface functional groups, leading to the restacking of the graphene layer which formed the graphite [43]. The diffraction peak at $18.2^{\circ}$ in the XRD patterns corresponds to PTFE [44].

The surface chemistry of GO before and after the electrochemical reduction was characterized using XPS, as shown in Figure 3. The C1s XPS spectrum of GO shows four different peaks centered at 284.4, 285.6286 .5 and $288 \mathrm{eV}$, which are corresponding to $\mathrm{C}=\mathrm{C} / \mathrm{C}-\mathrm{C}$ in aromatic rings, $\mathrm{C}-\mathrm{OH}, \mathrm{C}-\mathrm{O}$ (epoxy and alkoxy), and $\mathrm{C}=\mathrm{O}$ groups,

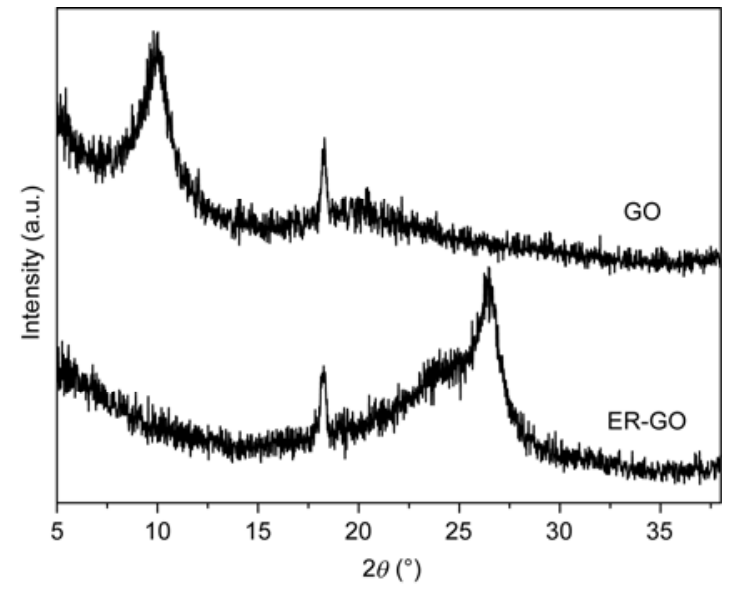

Figure 2 XRD patterns of the GO and ER-GO films. 


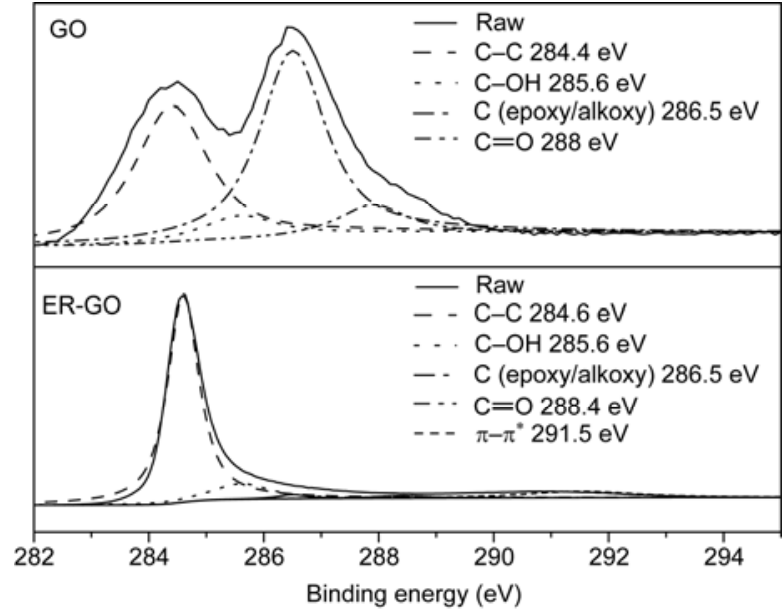

Figure 3 C1s high-resolution XPS spectra of the GO and ER-GO films.

respectively. After the electrochemical reduction, the intensities of all $\mathrm{C} 1 \mathrm{~s}$ peaks of the carbons binding to oxygen, especially the peak of $\mathrm{C}-\mathrm{O}$ (epoxy and alkoxy), decrease dramatically compared to that of GO, revealing that most oxygen containing functional groups are removed. In addition, the $\pi \rightarrow \pi^{*}$ shake-up satellite peak around $291.5 \mathrm{eV}$, a characteristic of aromatic or conjugated systems [41], is observed for ER-GO. According to the semi-quantitative analysis of XPS, the O/C atomic ratio of ER-GO is $1.29 \%$. The strongly $\mathrm{KOH}$ solution can be used as reductant to chemically reduce GO [37]. So, in our experiments, this is a positive effect of using strongly $\mathrm{KOH}$ solution as electrolyte for electrochemical reduction, which is contributed to a lower oxygen content. These results, combined with XRD, indicate the structural changes from graphene oxide to graphene.

The topographies of the GO and ER-GO films were characterized by AFM, as shown in Figure 4. The surface roughness $\left(R_{\mathrm{a}}\right)$ of the GO and ER-GO films were $\sim 47$ and $\sim 177 \mathrm{~nm}$, respectively. After the electrochemical reduction of GO, the ER-GO film shows a more large wrinkle and a rougher surface than the GO film. Such rough surface may facilitate the penetration and diffusion of electrolyte ions.

Figure 5 shows the Raman spectra of GO and ER-GO films, and the bands associated at $\sim 1330$ and $\sim 1600 \mathrm{~cm}^{-1}$ correspond to $D$ and $G$ modes, respectively. After electrochemical reduction, the $D / G$ intensity ratio increases from 0.95 to 1.15 . This change in the intensity ratio of the $D / G$ is attributed to the increased defect concentration present in ER-GO relative to that in GO [24,34].

Figure 6 presents the Nyquist plots of the GO and ERGO films. The ER-GO film has a better capacitive performance than that of the GO film, as the line of the ER-GO film is more vertical. The intersection of the curve at the $\mathrm{X}$-axis represents the internal or equivalent series resistance (ESR). The slope of the $45^{\circ}$ portion of the curve is called the Warburg resistance and is a result of the frequency
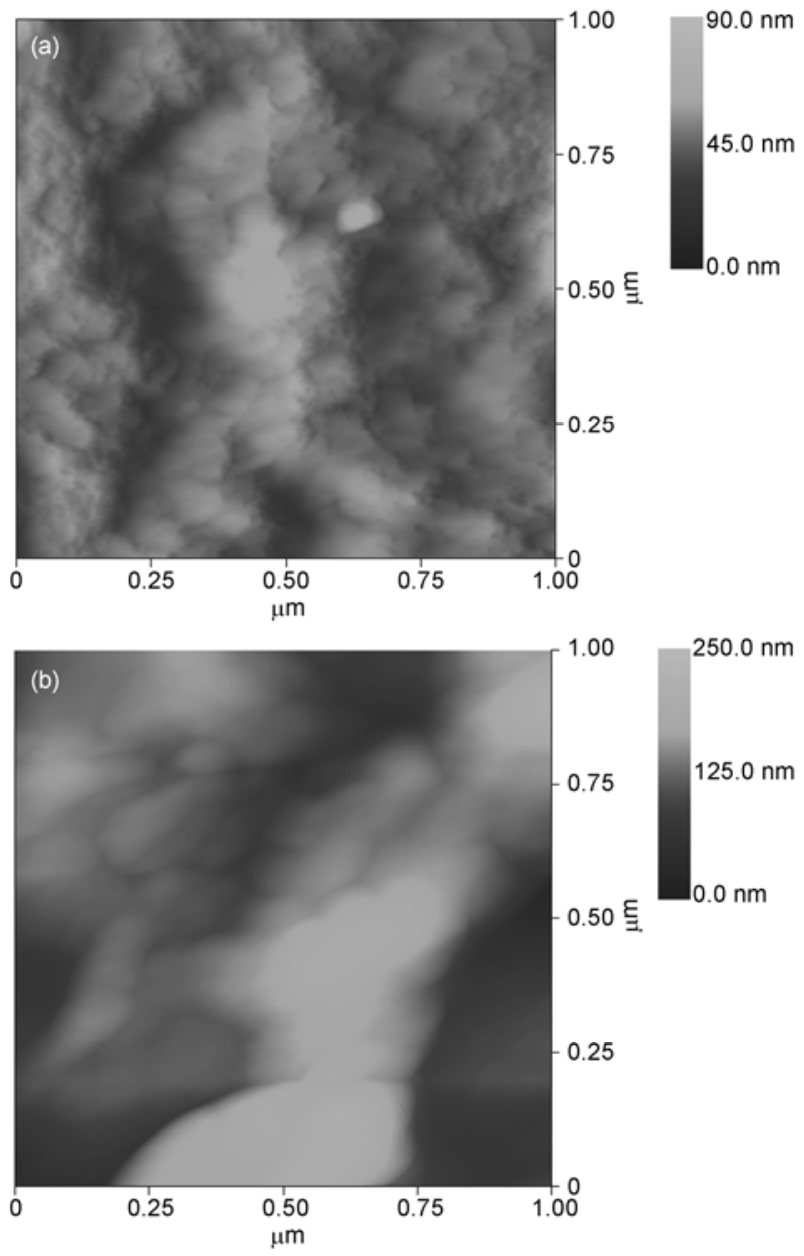

Figure 4 AFM images of GO (a) and ER-GO films (b).

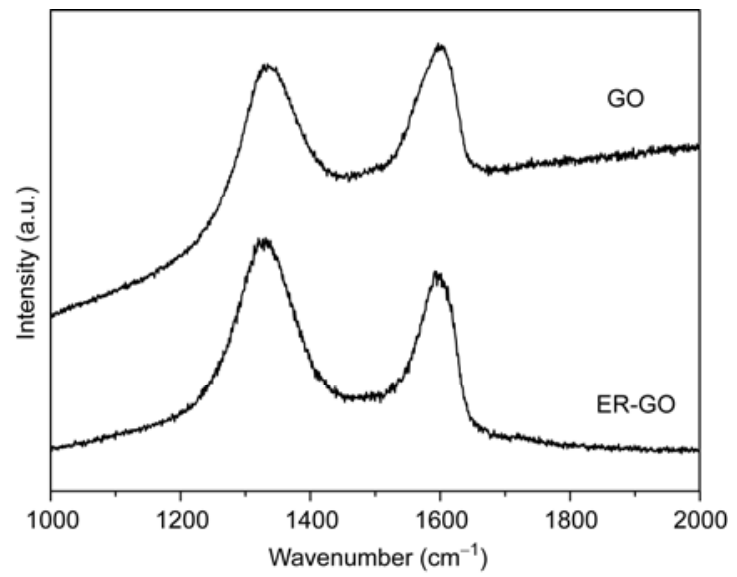

Figure 5 Raman spectra of the GO and ER-GO films.

dependence of ion diffusion/transport in the electrolyte [11]. The GO film shows a much larger Warburg resistance, which is due to its poor conductivity. The inset of Figure 6 shows the high-frequency region of the impedance spectra for the GO and ER-GO films. The internal resistance was 0.72 and $0.65 \Omega$ for the GO and ER-GO films, respectively. 

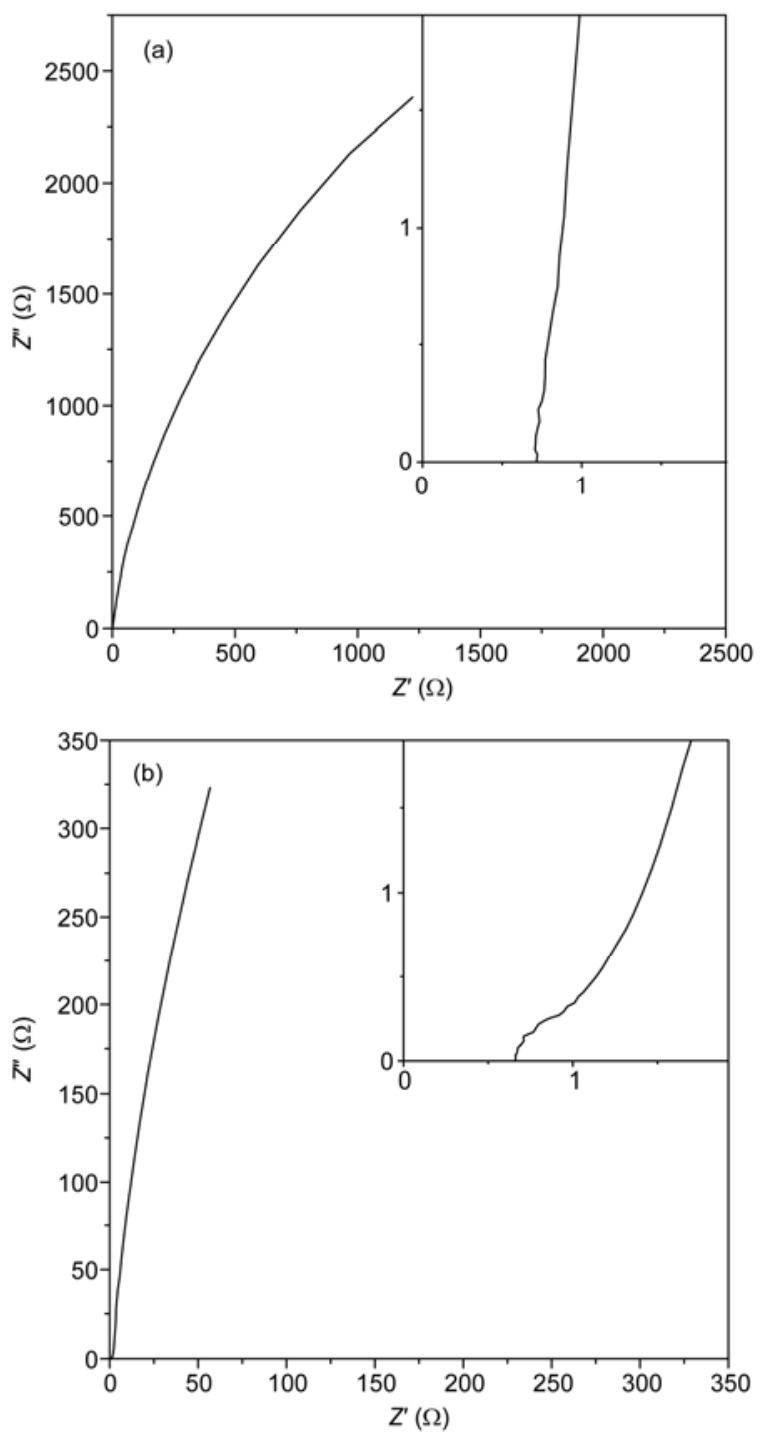

Figure 6 Nyquist plots of GO (a) and ER-GO films (b).

Figure 7 shows the CV curves of the ER-GO film at the scan rates of $0.1,0.3,0.5,1$ and $2 \mathrm{~V} \mathrm{~s}^{-1}$. It can be seen that all $\mathrm{CV}$ curves retain a similar shape in the potential window from -0.9 to $0 \mathrm{~V}$ (vs. $\mathrm{Hg} / \mathrm{HgO}$ ). Even at an ultrafast scan rate of $2 \mathrm{~V} \mathrm{~s}^{-1}$, the $\mathrm{CV}$ curve is still quasi-rectangular in shape along the current-potential axis, without any redox peaks. This demonstrates excellent capacitance behavior and fast diffusion of electrolyte ions into the electrode.

Figure 8(a) shows the galvanostatic discharge curves of the ER-GO film between -0.9 to $0 \mathrm{~V}$ at different current densities of 5, 8, 10, 20, 50 and $100 \mathrm{~A} \mathrm{~g}^{-1}$, respectively. The specific capacitance of the electrode measured by the galvanostatic discharge method can be calculated from the equation [45]:

$$
C=\frac{I \Delta t}{\Delta V m},
$$

where $C\left(\mathrm{~F} \mathrm{~g} \mathrm{~g}^{-1}\right)$ is the specific capacitance, $I$ is the constant

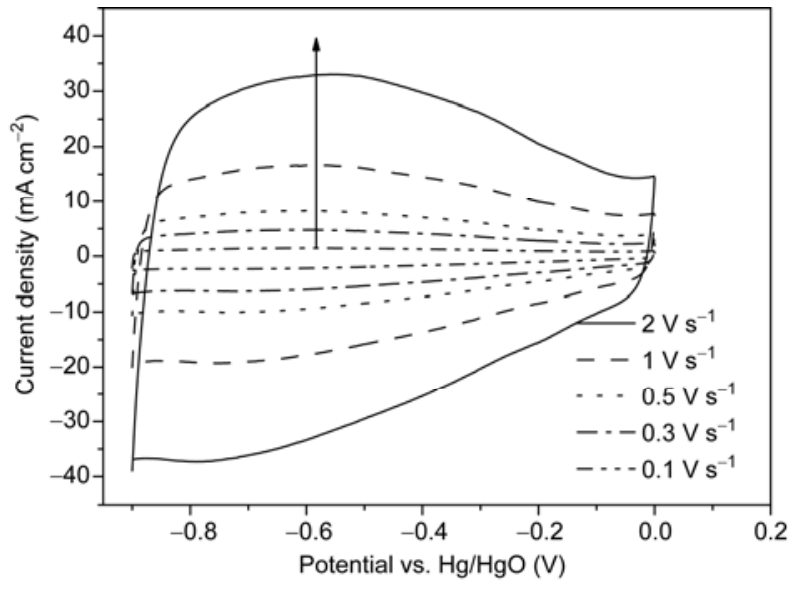

Figure $7 \mathrm{CV}$ curves of the ER-GO film at different scan rates from 0.1 to $2 \mathrm{~V} \mathrm{~s}^{-1}$.

discharge current, $\Delta t$ is the discharge time, $\Delta V$ is the potential window, and $m(\mathrm{~g})$ is the mass of the active material in the electrode. According to this equation, the specific capacitance of the ER-GO film at the current density of $5 \mathrm{~A} \mathrm{~g}^{-1}$ is $152 \mathrm{~F} \mathrm{~g}^{-1}$. This value is comparable with or higher than that of electrochemical reduction graphene oxides reported by other routes $[31,32,35]$. However, the specific capacitance of the GO film is only $8.9 \mathrm{~F} \mathrm{~g}^{-1}$ at the current density of $5 \mathrm{~A} \mathrm{~g}^{-1}$. Generally, the specific capacitance gradually decreases with the increase of current density, which can be attributed to the low utilization efficiency of active materials under a high discharge current. The capacitance retention is about $60 \%$, with growth of current densities from 5 to $20 \mathrm{~A} \mathrm{~g}^{-1}\left(92 \mathrm{~F} \mathrm{~g}^{-1}\right)$, Further increasing the current density to $100 \mathrm{~A} \mathrm{~g}^{-1}$, the specific capacitances almost keep constant, which indicates a high utilization efficiency and good rate capability (Figure 8(b)).

To evaluate the stability of the ER-GO film, the values of specific capacitance with respect to the cycle numbers at a constant current density of $10 \mathrm{~A} \mathrm{~g}^{-1}$ are measured and the corresponding result is shown in Figure 9. The ER-GO film exhibits excellent long cycle life with $99 \%$ specific capacitance retained after 3000 cycles. This demonstrates excellent cycle stability and reversibility of the ER-GO film in the repetitive charge/discharge cycling, and suggests that the ER-GO film could be a promising electrode material for EDLCs.

The excellent electrochemical properties obtained can be attributed to the special structural characteristic of the ER-GO film. The low $\mathrm{O} / \mathrm{C}$ ratio leads to a good conductivity of the ER-GO film, which can facilitate the fast transport of the electrons. The electrochemical reduction of GO can efficiently expose electrochemically active sites. Addition of PTFE binder can make graphene nanosheets have good adhesion to the substrate. Furthermore, the present work may provide a simple method to produce graphene films with controllable thickness and size. 

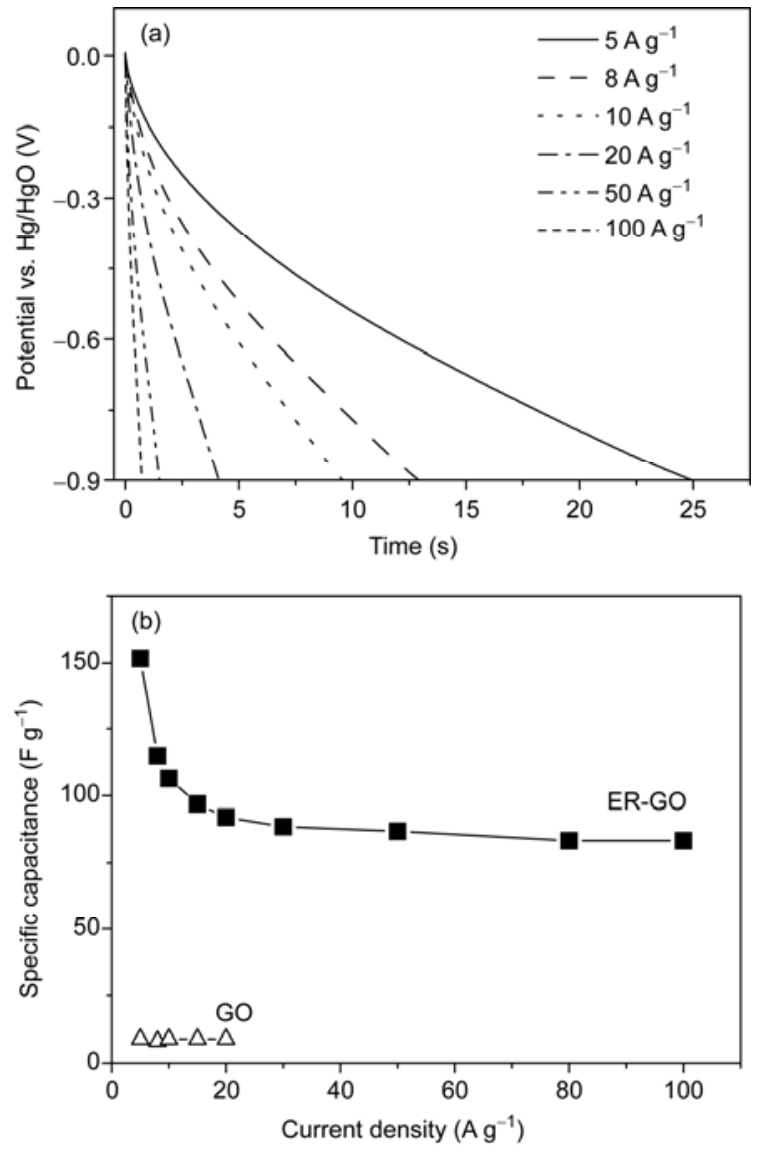

Figure 8 (a) Discharge curves of the ER-GO film at different current densities from 5 to $100 \mathrm{~A} \mathrm{~g} \mathrm{~g}^{-1}$; (b) specific capacitance of the GO and ER-GO films as a function of current density.

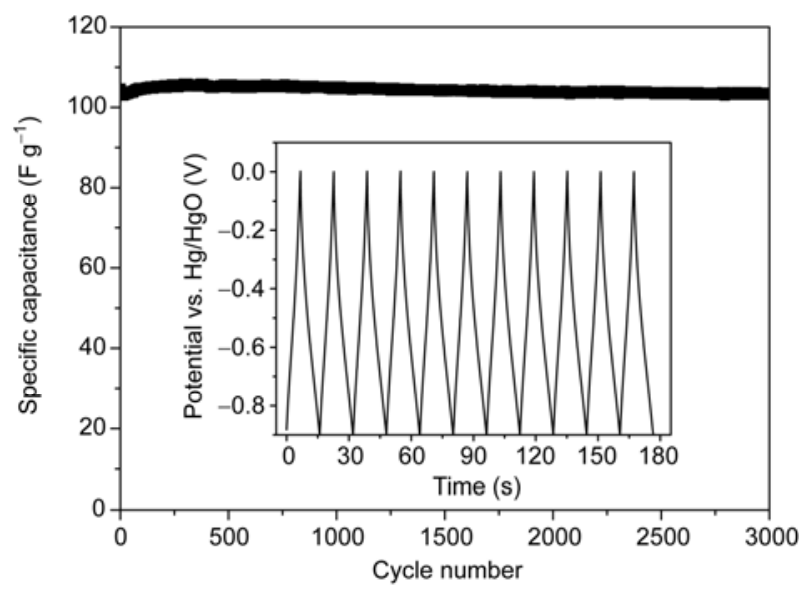

Figure 9 Cycle life of the ER-GO film measured at $10 \mathrm{~A} \mathrm{~g}^{-1}$ and its galvanostatic charge-discharge curve (inset).

\section{Conclusions}

In summary, a simple, efficient, and environmentally friendly electrochemical method has been developed to produce ER-GO film with a low O/C ratio of $1.29 \%$. The ER-GO film shows a specific capacitance of $152 \mathrm{~F} \mathrm{~g}^{-1}$ at the current density of $5 \mathrm{~A} \mathrm{~g}^{-1}$ in $6 \mathrm{~mol} \mathrm{~L}^{-1} \mathrm{KOH}$ aqueous solution. Moreover, the ER-GO film preserves $99 \%$ of its initial capacitance after 3000 cycles. Such excellent electrochemical performance makes the ER-GO film as a promising electrode material for EDLCs.

This work was partially supported by the Knowledge Innovation Program of the Chinese Academy of Sciences (KJCX2-YW-W26), Beijing Municipal Science and Technology Commission (Z111100056011007), and the National Natural Science Foundation of China (21001103 and 51025726).

1 Geim A K. Graphene: Status and prospects. Science, 2009, 324: 1530-1534

2 Zhu Y W, Murali S, Cai W W, et al. Graphene and graphene oxide: Synthesis, properties, and applications. Adv Mater, 2010, 22: 39063924

3 Novoselov K S, Jiang Z, Zhang Y, et al. Room-temperature quantum hall effect in graphene. Science, 2007, 315: 1379

4 Feng X M, Li R M, Ma Y W, et al. One-step electrochemical synthesis of graphene/polyaniline composite film and its applications. Adv Funct Mater, 2011, 21: 2989-2996

5 Zhang Q O, He Y Q, Chen X G, et al. Structure and photocatalytic properties of $\mathrm{TiO}_{2}$-graphene oxide intercalated composite. Chin Sci Bull, 2011, 56: 331-339

6 Zhang D, Zhang X, Chen Y, et al. Enhanced capacitance and rate capability of graphene/polypyrrole composite as electrode material for supercapacitors. J Power Sources, 2011, 196: 5990-5996

7 Zhang X, Sun X, Chen Y, et al. One-step solvothermal synthesis of graphene/ $\mathrm{Mn}_{3} \mathrm{O}_{4}$ nanocomposites and their electrochemical properties for supercapacitors. Mater Lett, 2012, 68: 336-339

8 Chen Y, Zhang X, Zhang D, et al. One-pot hydrothermal synthesis of ruthenium oxide nanodots on reduced graphene oxide sheets for supercapacitors. J Alloys Compd, 2012, 511: 251-256

9 Tian L L, Zhuang Q C, Li J, et al. Mechanism of intercalation and deintercalation of lithium ions in graphene nanosheets. Chin Sci Bull, 2011, 56: 3204-3212

10 Liu H M, Yang W S. Ultralong single crystalline $\mathrm{V}_{2} \mathrm{O}_{5}$ nanowire/ graphene composite fabricated by a facile green approach and its lithium storage behavior. Energy Environ Sci, 2011, 4: 4000-4008

11 Stoller M D, Park S, Zhu Y, et al. Graphene-based ultracapacitors. Nano Lett, 2008, 8: 3498-3502

12 Zhang L L, Zhou R, Zhao X S. Graphene-based materials as supercapacitor electrodes. J Mater Chem, 2010, 20: 5983-5992

13 Miller J R, Outlaw R A, Holloway B C. Graphene double-layer capacitor with ac line-filtering performance. Science, 2010, 329: 1637-1639

14 Zhu Y W, Murali S, Stoller M D, et al. Carbon-based supercapacitors produced by activation of graphene. Science, 2011, 332: 1537-1541

15 Wang $\mathrm{H} \mathrm{W}, \mathrm{Wu} \mathrm{H} \mathrm{Y}$, Chang Y Q, et al. Tert-butylhydroquinonedecorated graphene nanosheets and their enhanced capacitive behaviors. Chin Sci Bull, 2011, 56: 2092-2097

16 Du X, Guo P, Song H, et al. Graphene nanosheets as electrode material for electric double-layer capacitors. Electrochim Acta, 2010, 55: 4812-4819

17 Chen Y, Zhang X, Yu P, et al. Electrophoretic deposition of graphene nanosheets on nickel foams for electrochemical capacitors. J Power Sources, 2010, 195: 3031-3035

18 Chen Y, Zhang X, Zhang D, et al. High performance supercapacitors based on reduced graphene oxide in aqueous and ionic liquid electrolytes. Carbon, 2011, 49: 573-580

19 Chen Y, Zhang X, Zhang D, et al. High power density of graphene-based supercapacitors in ionic liquid electrolytes. Mater Lett, 2012, 68: 475-477

20 Novoselov K S, Geim A K, Morozov S V, et al. Electric field effect 
in atomically thin carbon films. Science, 2004, 306: 666-669

21 Berger C, Song Z M, Li X B, et al. Electronic confinement and coherence in patterned epitaxial graphene. Science, 2006, 312: 11911196

22 Mattevi C, Kim H, Chhowalla M. A review of chemical vapour deposition of graphene on copper. J Mater Chem, 2011, 21: 3324-3334

23 Lv W, Tang D M, He Y B, et al. Low-temperature exfoliated graphenes: Vacuum-promoted exfoliation and electrochemical energy storage. ACS Nano, 2009, 3: 3730-3736

24 Stankovich S, Dikin D A, Piner R D, et al. Synthesis of graphenebased nanosheets via chemical reduction of exfoliated graphite oxide. Carbon, 2007, 45: 1558-1565

25 Li D, Muller M B, Gilje S, et al. Processable aqueous dispersions of graphene nanosheets. Nat Nanotechnol, 2008, 3: 101-105

26 Park S, Ruoff R S. Chemical methods for the production of graphenes. Nat Nanotechnol, 2009, 4: 217-224

27 Kotov N A, Dekany I, Fendler J H. Ultrathin graphite oxide-polyelectrolyte composites prepared by self-assembly: Transition between conductive and non-conductive states. Adv Mater, 1996, 8: 637-641

28 Wang Z, Zhou X, Zhang J, et al. Direct electrochemical reduction of single-layer graphene oxide and subsequent functionalization with glucose oxidase. J Phys Chem C, 2009, 113: 14071-14075

29 Hilder M, Winther-Jensen B, Li D, et al. Direct electro-deposition of graphene from aqueous suspensions. Phys Chem Chem Phys, 2011, 13: 9187-9193

30 Zhou M, Wang Y L, Zhai Y M, et al. Controlled synthesis of largearea and patterned electrochemically reduced graphene oxide films. Chem Eur J, 2009, 15: 6116-6120

31 Shao Y Y, Wang J, Engelhard M, et al. Facile and controllable electrochemical reduction of graphene oxide and its applications. J Mater Chem, 2010, 20: 743-748

32 Peng X Y, Liu X X, Diamond D, et al. Synthesis of electrochemicallyreduced graphene oxide film with controllable size and thickness and its use in supercapacitor. Carbon, 2011, 49: 3488-3496

33 Guo H L, Wang X F, Qian Q Y, et al. A green approach to the synthesis of graphene nanosheets. ACS Nano, 2009, 3: 2653-2659
34 Ramesha G K, Sampath S. Electrochemical reduction of oriented graphene oxide films: An in situ Raman spectroelectrochemical study. J Phys Chem C, 2009, 113: 7985-7989

35 Liu S, Ou J F, Wang J Q, et al. A simple two-step electrochemical synthesis of graphene sheets film on the ITO electrode as supercapacitors. J Appl Electrochem, 2011, 41: 881-884

36 Harima Y, Setodoi S, Imae I, et al. Electrochemical reduction of graphene oxide in organic solvents. Electrochim Acta, 2011, 56: 53635368

37 Fan X B, Peng W C, Li Y, et al. Deoxygenation of exfoliated graphite oxide under alkaline conditions: A green route to graphene preparation. Adv Mater, 2008, 20: 4490-4493

38 Chen Y, Zhang X, Yu P, et al. Stable dispersions of graphene and highly conducting graphene films: A new approach to creating colloids of graphene monolayers. Chem Commun, 2009, 4527-4529

39 Frackowiak E, Metenier K, Bertagna V, et al. Supercapacitor electrodes from multiwalled carbon nanotubes. Appl Phys Lett, 2000, 77: 2421-2423

40 Bao Q L, Bao S J, Li C M, et al. Supercapacitance of solid carbon nanofibers made from ethanol flames. J Phys Chem C, 2008, 112: 3612-3618

41 Xu B, Yue S F, Sui Z Y, et al. What is the choice for supercapacitors: Graphene or graphene oxide? Energy Environ Sci, 2011, 4: 28262830

42 Uhm S, Tuyen N H, Lee J. Controlling oxygen functional species of graphene oxide for an electro-oxidation of L-ascorbic acid. Electrochem Commun, 2011, 13: 677-680

43 McAllister M J, Li J L, Adamson D H, et al. Single sheet functionalized graphene by oxidation and thermal expansion of graphite. Chem Mater, 2007, 19: 4396-4404

44 Wang F, Arai S, Endo M. Electrochemical preparation and characterization of nickel/ultra-dispersed PTFE composite films from aqueous solution. Mater Trans, 2004, 45: 1311-1316

45 Han Y Q, Ding B, Zhang X G. Effect of feeding ratios on the structure and electrochemical performance of graphite oxide/polypyrrole nanocomposites. Chin Sci Bull, 2011, 56: 2846-2852

Open Access This article is distributed under the terms of the Creative Commons Attribution License which permits any use, distribution, and reproduction in any medium, provided the original author(s) and source are credited. 